\title{
ONEIROCRITICS AND MIDRASH
}

\section{On Reading Dreams and the Scripture}

\author{
Erik Alvstad
}

\begin{abstract}
$\propto$
Ав в T RAC T In the context of ancient theories of dreams and their interpretation, the rabbinic literature offers particularly interesting loci. Even though the view on the nature of dreams is far from unambiguous, the rabbinic tradition of oneirocritics, i.e. the discourse on how dreams are interpreted, stands out as highly original. As has been shown in earlier research, oneirocritics resembles scriptural interpretation, midrash, to which it has lent some of its exegetical rules. This article will primarily investigate the interpreter's role in the rabbinic practice of dream interpretation, as reflected in a few rabbinic stories from the two Talmuds and from midrashim. It is shown that these narrative examples have some common themes. They all illustrate the polysemy of the dream-text, and how the person who puts an interpretation on it constructs the dream's significance. Most of the stories also emphasize that the outcome of the dream is postponed until triggered by its interpretation. Thus the dreams are, in a sense, pictured as prophetic - but it is rather the interpreter that constitutes the prophetic instance, not the dream itself. This analysis is followed by a concluding discussion on the analogical relation between the Scripture and the dream-text, and the interpretative practices of midrash and oneirocritics.
\end{abstract}

\footnotetext{
7 he striking similarities between the rabbinic traditions of Scriptural exegesis, midrash, and the rabbinic practice of dream interpretation, oneirocritics, have long since been
} 
recognized. In a pioneering study Saul Lieberman not only showed that these interpretational practices resembled each other, but also argued convincingly that some of the hermeneutic rules of aggadic midrash probably were derived from ancient rules of dream interpretation. ${ }^{1}$ This insight provides the background to the present study, which primarily will investigate how the interpretation of dreams was conceived of during the Talmudic era, as attested in the rabbinic literature.

My main focus will be confined to some aspects of the nature of interpretation and the interpreter's role in rabbinic dream interpretation. To some extent I will also discuss the relation of oneirocritics to midrash. Through the analysis of a number of rabbinic stories in which dream-interpreters, primarily rabbis, play the principal parts I will show that the reader's participation in the construction of the dream-text's meaning is a predominant theme. ${ }^{2}$ These stories might be characterized as narratives of interpretation, exemplifying the rabbinic practice of creative exegesis in dream interpretation. In the article's final part the analogy between the dream-text and the Scripture, and the resemblance between the cultural practices of dream interpretation and scriptural interpretation, will be considered.

It might be claimed that in the rabbinic culture of Late Antiquity the interpretation of dreams was a marginal interpretative practice, compared to that of scriptural exegesis. But the significance of dreams and their interpretation during the Talmudic era must not be underestimated, as Hasan-Rokem writes: „Dreams have been given a privileged position in Jewish culture since biblical times» (1999: 214). Even though the scope of this article will not be as wide as that of the significance of dreams in Jewish culture generally, I think that this study will show that the rabbinic discourse on dreams and their interpretation is important when considering also general questions of rabbinic textual politics, authority, and interpretative freedom and restraint.

\section{Reading the Dream-text}

A famous dictum in the so-called Talmudic Dreambook (bBer 55a$57 \mathrm{~b}$ ) asserts that "All dreams follow the mouth» rjt ohfkuv ,unukjv kf vpv. ${ }^{3}$ This dictum, which recurs a couple of times in the Dreambook, is usually understood to mean that ultimately the meaning of a dream is determined by its interpretation. That is, a dream has no other sig- 
nificance than that ascribed to it by a rabbinic sage or another interpreter of dreams. The dream follows the mouth of the interpreter in the sense that the meaning and result of the dream are decided by the interpreter and the interpretation he puts on the dream. This seems to be the import of a tradition ascribed to R. Bana'ah, which is concluded by this dictum:

There were twenty-four interpreters of dreams in Jerusalem. Once I dreamt a dream and I went round to all of them and they all gave different interpretations, and all were fulfilled, thus confirming that which is said: All dreams follow the mouth. (bBer 55b) ${ }^{4}$

At the outset of this narrative the dream itself is pictured as a formless void of pure potentiality (»I dreamt a dream»), but at the moment that the interpreters make their interpretations the dream is given meaning in a simultaneous act of articulation and creation. The meanings that the interpreters read into this void are, as it were, at the same time actualized (»they all gave different interpretations») and effectuated (»and all were fulfilled») by the interpretation. This stance also allows different interpreters to put different interpretations on the same dream - interpretations that will all be fulfilled irrespective of the dream's content. Thus the focus is solely on the interpreter, and not on the dream-text that he interprets, or the dreamer who dreamt the dream. Both dream-text and dreamer are pictured as fundamentally irrelevant. $^{5}$

A similar opinion on the relation between dream, dreamer and interpreter might be inferred from another well-known dictum, which is ascribed to R. Hisda and repeated a couple of times in the Dreambook: »A dream which is not interpreted is like a letter that is not read» thren tks t,rdtF rapn tks tnkj (bBer 55a, 55b). Through this analogy between a dream and a letter the dictum makes an explicit parallel between dreams and texts, and it furthermore compares the act of dream interpretation to that of reading. With a slight shift in emphasis compared to the first dictum discussed above, which centres on the interpreters and the interpretative activity, this dictum focuses rather on that which is interpreted, i.e. the dream-text. But the dictum defines this dream-text negatively, as something that is constituted solely through reading/interpretation - and similarly to a letter that is 
left unread, a dream is nothing without its interpretation. In the same way that a text is given meaning through the reader's reading of the text, the dream is pictured as something that is constructed through interpretation, and in this it seems to be wholly in accord with the first dictum.

When encountering R. Hisda's comparison between a letter and a dream, one is tempted, quite naturally, to extend the metaphoric similarity of these two phenomena. Using the word »letter» as the keyword one might be inclined to probe further into the metaphoric domain of this word and to postulate other textual instances that are usually connected with a letter, and perhaps with most texts: If the dream is like a letter, i.e. a particular species of text, has it not some of the other specific characteristics that letters tend to have? Does not the dictum by using this metaphor disclose rabbinic opinions towards other aspects of the nature of dreams, as regards, for instance, the existence of a particular author or sender of the dream, and an authorial intention behind it, and perhaps some other features that are usually connected with letters? These are questions that Niehoff (1992: 58) touches upon when she writes that »The analogy to a letter further suggests that the dream might be regarded as a text with a specific intent, a particular addressee, and perhaps even a known author». But as for this dictum I think that the analogy between the letter and the dream should not be pushed too far. The concept of dreams which might be derived from the dictum (or from that mentioned earlier) does not comprise a specific authorial intent or original meaning in dreams; instead meaning and intent are pictured as created through interpretation, and not given in the dream. Contrary to what is usual with a letter, in dreams the question of a particular author or sender of the dream is very complicated. ${ }^{6}$ Even the concept of a particular addressee is, in a way, uncertain: it is not necessarily the dreamer that should be regarded as the addressee, since the crucial receivers of the dream are the interpreters who interpret the dreams according to their agendas (as in the story above where twenty-four dream interpreters appropriate R. Bana'ah's dream and put whatever interpretation they see fit upon it). ${ }^{7}$

The analogy between the dream and the text, and the corresponding one between oneirocritics and the act of reading, are unequivocal, and in fact permeate the whole rabbinic discourse on dreams. How- 
ever, the concepts of »text» and »reading» must here be envisaged in a particular way, precisely because ordinary notions of authorial intent, addressee, and author, i.e. some of the usual connotations of a letter, and of most texts, are cancelled, or at least have quite an ambiguous status in the context of rabbinic dreaming. This, I think, is a plausible conclusion considering the context where this principle appears for the second time in the Dreambook: ${ }^{8}$

Rav Huna bar Ammi said in the name of R. Pedat who had it from R. Yohanan: If one sees a dream which makes him sad he should go and have it interpreted in the presence of three.

Why should he have it interpreted?! Has not Rav Hisda said: A dream that is not interpreted is like a letter that is not read?

Say rather then, he should have a good turn given to it in the presence of three. Let him bring three and say to them: I have seen a good dream; and they should say to him, Good it is and good may it be. May the All-Merciful turn it to good; seven times may it be decreed from heaven that it should be good and may it be good. They should say three verses with the word hapak [turn], and three with the word padah [redeem] and three with the word shalom [peace]. (bBer $55 \mathrm{~b})^{9}$

By the invocation of R. Yohanan's statement it is at first suggested that the potentially bad dream should be countered by a favourable interpretation, made in the presence of three persons. This good interpretation is assumed to forestall the possibly bad consequences of the dream. But this solution is called into question by Talmud's anonymous editors, and by referring to Hisda's dictum they implicitly assert that it is better to leave the dream uninterpreted, since then it will not pose any hazard; by declining to interpret the dream one will not actualize it, and hence not the potential danger either. But the discussion is not concluded with this argument, and finally the decision seems to be reached that they should overrule Yohanan's statement and heed both Hisda's dictum by leaving the dream uninterpreted, and the suggestion that certain biblical verses should be read by three persons, to really be on the safe side and provide a kind of »double insurance». ${ }^{10}$

But how is the letter metaphor to be understood in this context? R. Yohanan's statement and the editorial gloss on it that uses R. Hisda's principle both agree that the interpreters in some way are able to actualize the dream by »reading» it, and thus make it come into effect; but 
whereas the former statement seems to believe in the interpreters' ability also to reverse the potential bad consequences it might have, by imposing a positive interpretation on it, the editors are against taking this risk, and instead argue that the dream be left alone. They confine themselves to pronouncing protective biblical verses upon it. Yet they both agree that it is possible to miraculously turn worrying dreams into something good through the act of reading. ${ }^{11}$ But apart from establishing the significant metaphorical parallel between a dreamtext and a letter, further analogies between these two species of text might be somewhat tenuous. If the dream is like a letter, in the context of rabbinic dream theory this letter seems, more often than not, to be regarded as sent anonymously, with an unclear intention and an indeterminate message, and on its envelope is written "to whom it may concern». ${ }^{12}$

Finally, some remarks on the concept of authorship in the context of these two dicta. Since the interpreter is not only the actual receiver of the dream (»A dream which is not interpreted is like a letter that is not read»), and hence its real addressee, but also the instance where the import of the dream is articulated (»All dreams follow the mouth»), the interpreter might also be characterized as the author of the dream. Thus, according to these dicta, the interpretation depends neither on the dreamer as the producer of meaning (as is the case in Freud's dream interpretation) ${ }^{13}$ nor necessarily on some external system of symbols (as in interpretations proceeding from traditional catalogues of dream omina, or from the juxtaposition of dream-texts to biblical verses). The interpretation is to a considerable extent dependent on the reader and the act of reading. In a way one can say that the rabbis resemble reader-response critics in that they held that the true »author» of the dream was the one who interpreted it, because the only meaning a dream has is that which the interpreter gives it. The dream in itself is without meaning; hence it is the dream-interpreter who is the author of the dream. ${ }^{14}$ This attitude, the reader-response critic Norman Holland (1993: xvii) suggests, is precisely the attitude that a reader-response critic is likely to hold towards dreams and their interpretation. ${ }^{15}$ The reader's active participation in the creation of textual meaning is also one of the prime characteristics of rabbinic midrash. In this respect the rabbi's approaches to the dream and the Bible are similar, and the fact 
that the practice of oneirocritics and that of scriptural exegesis bear a close resemblance to each other as regards the reader-text relationship is, as I will discuss later, no coincidence. I will return to these questions in the final chapter, but will first elaborate on how the reading or interpreting of dreams is pictured in rabbinic literature.

\section{Oneiric Creativity: Stories about Dream Interpretation}

I propose that three interrelated conclusions about the rabbinic view on dreams and their interpretation can be deduced from the two axiomatic dicta discussed above: (1) The meaning of a dream is created by an interpreter through interpretation. (2) Dreams are "polysemantic» in the sense that a single dream has the potential to be realized in several different ways. (3) The efficacy of a dream (its capacity to produce results and influence external reality - to »come true») is wholly dependent on what the interpreter says it will effectuate (and not on the dream's content per se).

However, the fundamentals of this view are not restricted to the two passages from the Babylonian Talmud discussed earlier. The three distinct features of rabbinic dream-theory proposed above represent a general tendency discernible in the rabbinic literature. This assertion will be substantiated through a few more narrative examples. I have chosen to take these examples from different rabbinic collections, to emphasize that the attitude towards dreams and their interpretations which manifests itself in these two dicta is not confined to a specific rabbinic document, or a particular treatise on dreams, differing from the others or with its own agenda (e.g. the Dreambook in Talmud Bavli). To illustrate my point, I will relate a story, as it is given in one of the earlier amoraic Palestinian midrashim, the exegetical midrash on Lamentations:

A woman came to R. Eleazar and said, 'I dreamt that the beam of the house was split.' He told her, 'You will bear a son.' She departed and it happened so.

On another occasion she came to inquire of him and said, 'I dreamt that the beam of the house was split.' He told her, 'You will bear a son.' She departed and it happened so.

A third time she came to him and found the disciples assembled in the school, but their teacher was not present. She 
asked them, 'Where is your teacher?' They said, 'What do you want of him?' She said to them, 'Perhaps you are as wise as your teacher to interpret a dream that I saw.' They said to her, 'Tell us what you require and we will interpret it for you.' She told them, 'I dreamt that the beam of the house was split.' They replied, 'You will bury your husband.'

When she left them she began to cry. R. Eleazar heard this and asked them, 'Why is this woman crying?' They answered, 'She came to inquire of you but did not find you.' He said to his disciples, 'What did she come to ask?' 'To interpret a dream,' they said. 'And what did you tell her?' They informed him; and he thereupon said to them, 'You have killed a man; for is it not written, And as he interpreted for us, so it came to pass? ${ }^{16}$ And did not R. Yohanan say, "A dream follows its interpretation, except when it is of wine; some dream they are drinking it and it is a good omen, while others dream they are drinking it and it is a bad omen»?'

R. Abbahu said: Dreams are of no consequence either for good or for ill. (LamR I.1.18) ${ }^{17}$

During a period of time, which given the content of the story must be apprehended as at least a couple of years, a woman dreams the same dream on three different occasions, and each time she asks of R. Eleazar for an interpretation as regards the purport of the dream she had. While she succeeds in obtaining Eleazar's interpretations the first two times, and both times he offers auspicious interpretations about a child on its way, Eleazar happens to be absent the third time he is sought. Instead Eleazar's students jointly offer the woman an interpretation of her dream, an interpretation which predicts that her husband is going to die. Hence this thrice-repeated dream gets two different interpretations put on it; and while on the first two occasions the dream comes to pass according to the favourable interpretations given to it by Eleazar, the third time the dream is perhaps also fulfilled, but then, one might assume, in accordance with his students' fatal interpretation. The same dream is thus given two different interpretations, and the dream is presumably also fulfilled according to both of these interpretations, illustrating the possibility of multiple interpretations in rabbinic dream-theory, as well as how the very act of interpretation creates the meaning of the dream. The interpreter as the crucial agency in determining the outcome of a dream is emphasized through Eleazar's accusation against his students. Furthermore, his exclama- 
tion »You have killed a man!» comprises a critique of the students, who implicitly have appropriated his position by answering "yes» to the woman's question whether they were as wise as their teacher, and an assertion of the interpretative authority of the master against that of his students. Perhaps more distinctly than any other rabbinic dreamnarrative, this story also illustrates the perils of oneirocritics; the act of interpretation might be a dangerous enterprise, which if not curbed may have disastrous consequences. The assertion of the primacy of the interpretative agency is further underscored by R. Abbahu's concluding statement that "Dreams have no influence whatsoever», affirming the opinion that the dream-content is all but negligible as regards the importance and outcome of dreams, and emphasizing that »interpretation is the only game in town» (Fish 1980: 355).

A story in the Palestinian Talmud's tractate Ma'aser Sheni seems to hold a similar view regarding the nature of dreams and the possibility of multiple interpretations:

A person once came before R. Yose bar Halafta and told him, 'In a dream-vision, I was wearing a crown of olive branches.' R. Yose said to him, 'You will soon be exalted.'

Another person came and told him, 'In my dream-vision, I was wearing a crown of olive branches.' R. Yose said to him, 'You are going to be flogged.' He said to R. Yose, 'You told him he would soon be exalted, but you told me I am going to be flogged!?' R. Yose explained, 'I discerned that his olives were budding; yours, by contrast, were ready to be pressed for their oil.' (yMS $4: 6$ )

In this story R. Yose bar Halafta puts different interpretations on two identical dreams dreamt by two men (as opposed to the story above, in which one dreamer is given two different interpretations by two different interpreters). This is, quite naturally, regarded as unfair by the man who receives the unfavourable interpretation, but R. Yose justifies the divergent interpretations with reference to what he as interpreter could perceive in the other men's dream-visions!

When R. Yose claims he has immediate access to the dreamers' visions, similarly to a film critic watching a film, he renders unnecessary the dreamers' mediation of the dreams to the interpreter, usually executed through a translation of the dreams' visual (or aural) experience into words. That is, typically the interpreter is working with a representation of the dream that is mediated through language, a 
sort of reflected image of the phenomenon that he is supposed to work with, as Walde (1999: 131) characterizes this interpretative situation: »The narration of a dream does not reproduce the dream's incoherent thought processes in pure form. When dream images, usually consisting of pictures, are transformed into language, the interpreter is already working with a mediated and rationalized construct». However, this is apparently not the case in this story, since R. Yose appears to circumvent the dreams as mediated constructs, conveyed through the dreamers' narrations, and instead is pictured as having an unmediated access to the dreams in their "pure form». Thereby the complex interplay of different semiotic levels - the interplay, as Hasan-Rokem (1999: 213) puts it, between the seen and the heard, the spoken and the shown - that usually characterize dreams and the communications of dreams to people other than the dreamer, and in fact even to the dreamers themselves, is abolished. But the role of the interpreter is certainly not reduced, since he is endowed with almost supernatural powers. This story, then, gives a new interesting dimension to the question of oneirocritical authority, and also to that of the representational status of dreams in rabbinic culture.

Nevertheless, the case that I plead for here, i.e. the autonomy of the interpretation vis-à-vis the dream-text, might at first be considered somewhat weakened by the fact that R. Yose explicitly refers to the dream-content when putting his interpretations on the dreams. This circumstance might be conceived as something that clashes with the opinion that dreams in themselves are irrelevant (an opinion that perhaps reverberates in, for example, R. Abbahu's statement that »Dreams have no influence whatsoever»). Obviously the dream itself plays a prominent role in this story, but it is nevertheless the dream-content as conceived by the interpreter that counts in this story, not primarily any visions reproduced in narrative form by the dreamers. In this respect the narrative not only effectively asserts the authority of the interpreter against that of the dreamers, i.e. the priority of the reader over the author of the texts, but it also emphasizes the rabbis' extraordinary skills and supernatural insights. This attitude seems to be quite similar to that of reader-response critics, even though they usually refrain from ascribing preternatural powers to the readers, as is done to $\mathrm{R}$. Yose and his particular acts of reading in this story. 
Even so, when reading this story one might suspect that the respectively auspicious and ominous interpretations given the dreamers are due to the fact that the interpretations somehow, although not spelt out in this story, are connected with the personalities of the dreamers. Is it not reasonable to infer from R. Yose's differing interpretations that he makes an evaluation of situational specifics and the dreamers' personalities, not accounted for in this terse story, and then makes his interpretations? Possibly so; it was certainly not unusual that the rabbis, or other ancient dream interpreters, took the character of the dreamer, and a host of other external factors, into consideration when interpreting dreams. But in this short dream-narrative, as in the majority of similar stories, there are in fact no traces of any contextualization or evaluation of the personalities of the individuals whose dreams were interpreted.

My third example, which structurally bears some resemblance to the story from Yerushalmi discussed above (an interpreter puts different interpretations on two identical dreams dreamt by two men), consists of a small portion taken from one of the most complex and fascinating dream-stories in the rabbinic literature: the story of the dream-interpreter Bar Hedya, who gave favourable interpretations to those who paid him, and unfavourable ones to those who did not (bBer 56a-56b). ${ }^{18}$ Rabbis Rava and Abaye dream a succession of identical dreams, and after each dream they ask Bar Hedya for an interpretation. Rava, who does not pay Bar Hedya anything, gets very bad interpretations put on all of his dreams, while Abaye, who pays him, consistently receives auspicious interpretations. In the first part of the story the two rabbis dream about reading texts, namely biblical verses, but this changes after seven dreams about seven different verses, and after that they both dream six dreams about other objects. To substantiate my point I think it will suffice to relate Bar Hedya's interpretations of the first two dreams dreamt by Rava and Abaye:

They said to him: In our dream we had to read the verse, Your ox shall be slaughtered before your eyes. ${ }^{19}$ To Rava he said: Your business will be a failure, and you will be so grieved that you will have no appetite to eat. To Abaye he said: Your business will prosper, and you will not be able to eat from sheer joy.

They then said to him: We had to read in our dream the verse, Though you beget sons and daughters, they shall not remain with 
you. ${ }^{20}$ To Rava he interpreted it in its unfavourable sense. To Abaye he said: You have numerous sons and daughters, and your daughters will be married and go away, and it will seem to you as if they have gone into captivity. (bBer 56a)

This extract from the Bar Hedya story (as well as the long story in its entirety) makes obvious the opinion that the significance of a dream is conceived as something created by the interpreter through interpretation. Moreover, the polysemantic character of dreams is unambiguously asserted, since each dream is read in two different ways at the same time. It is also indicated that Bar Hedya's predictions come true, and consequently Rava's situation gets worse throughout the first half of the story, until Rava finally begins to pay Bar Hedya's fee. ${ }^{21}$ After that, Bar Hedya's interpretations of Rava's dreams become auspicious, and accordingly Rava's luck takes a turn for the better. Hence, the fact that the dreams are fulfilled according to Bar Hedya's predictions illustrates the often encountered rabbinic opinion that the outcome of a dream depends solely on what the interpreter claims will be its outcome.

As mentioned, the first part of the Bar Hedya story describes the two rabbis' dreams about reading scriptural verses. The reading of biblical passages in dreams is a common motif in rabbinic dream-stories. This is interesting, not least because it indicates that the interpreter seems to regard the biblical verse as a dream-text. When Bar Hedya uses the scriptural verses dreamt by Rava and Abaye to predict their future, he treats these scriptural verses as if they were accounts of »ordinary» premonitory dreams. By treating the scriptural verse as an equivalent to the dream-text, it is implied in the story that these two text-types in fact belong to similar textual categories. I will discuss this analogy between Scripture and dream-text later.

As a final example of how the interpreter is pictured as an active participant, to say the least, in the creation of the dream-text's meaning, I will relate another story from the Palestinian Talmud. In some ways it is the most extraordinary story of them all. It tells how a certain cunning Samaritan decides to fool R. Ishmael ben Yose (who is depicted in both the Talmuds as one of the most famous tannaitic dreaminterpreters) by relating a false dream to him. ${ }^{22} \mathrm{R}$. Ishmael interprets the Samaritan's false dream, fully aware that it is not a real dream, and 
his gruesome interpretation is fulfilled, notwithstanding that it was not based on a genuine dream report at all:

A Samaritan once decided, 'I shall mystify the Jewish elder, R. Ishmael ben R. Yose, by falsely reporting a dream that no one can interpret.'

He came before him and said, 'In a dream-vision, I saw four cedars, four sycamores, a bundle of reeds, a cow hide, and this gentleman was sitting and thrashing.' R. Ishmael said to him, 'The gentleman's soul will soon expire; even though this was no dream, you will not leave without an interpretation! Four cedars represent the four posts of your death bed. Four sycamore trees represent its four legs. A bundle of reeds represents its bolster. The hide supports the straw. The cow represents the lattice that holds the mattress. And the gentleman sitting and thrashing - that gentleman languishes upon it, neither dead nor alive.'

And it came to pass just as R. Ishmael predicted, and the Samaritan trickster died a slow, disease-ridden death. (yMS $4: 6)^{23}$

This story might be considered an ironic illustration of both the dictum that "All dreams follow the mouth» (bBer 55b; bBer 56a) and R. Abbahu's statement that »Dreams have no influence whatsoever» (LamR I.1.18; GenR 68:12; bSan 30a). It emphasizes that the significance as well as the consequence of the Samaritan's »dream» are determined by the interpretation put on it by $\mathrm{R}$. Ishmael. But the radical move of this story, the way it carries the matter of interpretative autonomy vs. textual determinacy to its extremes, is that it portrays the act of interpretation as completely disengaged from any real dream-text. Using as hermeneutic keys the specifics given in the Samaritan trickster's mock dream, i.e. the four cedars, the bundle of reeds, the cow hide and the thrashing man, R. Ishmael produces a kind of interpretation which, similar to a curse, seems to bring about the death of the Samaritan. Hence the interpreter has the decisive role in this story, as is usual, but here the dream-text is absent altogether, replaced by an entirely different text: the Samaritan's tall tale, in itself utterly devoid, one would presume, of prophetic qualities. Instead it is the interpreter R. Ishmael that is endowed with supernatural powers in this story, as was the case in the story discussed above about R. Yose, which was also from the Palestinian Talmud. And similarly to this narrative, but through a different strategy, the story about Ishmael's dealings with the Samaritan 
trickster seems to undermine the whole concept of dream interpretation. While Zeitlin (1970: 15-18) could be right when he claims that the tannaitic sages did not consider dreams to be acts of divination, the interpretative activities of the same sages occasionally were. The rabbis are undoubtedly at times pictured as endowed with divine inspiration and with prophetic abilities, both in the realm of dream interpretation and in that of scriptural exegesis. ${ }^{24}$ However, the ironic ending of this story also gives the impression that the ability to predict people's fate might be something quite different, because in this case the rabbinic sage wields his interpretation as a powerful weapon, and uses it as a kind of malediction against the impudent. More than anything else, this story then dramatically illustrates the dangers in trying to trick or disgrace a rabbi, and the horrible consequences one might suffer when crossing a powerful sage. This is a polemical motif apparent in quite a few rabbinic dream-stories. ${ }^{25}$

I will conclude the discussion of these narrative examples. Even though the four stories are situated in different literary and cultural contexts, and have their own distinct character and agenda, ${ }^{26}$ some common themes are apparent in them. In various ways they all gloss upon the indeterminacy and the polysemy of the dream-text, and upon how, in want of a given meaning, the dream's significance is constructed by the person who appropriates it and puts an interpretation on it. This suggests not only that the interpreter has priority over the "author» of the dream-text (whether conceived of as the dreamer, or as God), but also that the interpreter might be considered the real author of it. Several of the stories also emphasize that the fulfilment of the dream is postponed until triggered by the interpretation put on it. Thus the dreams are, in a sense, pictured as prophetic - but it is rather the interpreter that constitutes the prophetic instance, not the dream itself. $^{27}$

In the context of ancient dream-theories these themes are quite original. While the attribution of different, and sometimes even contradictory, interpretations to a single dream is mentioned in antiquity, ${ }^{28}$ the idea that all of these multiple interpretations also have the potential to be fulfilled seems to be distinctive of rabbinic dreamtheory. And, as Alexander (1995: 236) concludes, there seem to be no parallels in ancient oneirocritical literature to the rabbinic conception 
that a dream is fulfilled according to the interpretation put on it. The conclusion that Alexander draws, quite correctly I think, is that this view of dreams and their interpretation reflects certain notions of textuality that were characteristic of the rabbinic culture. And not only did these distinct textual notions comprise the dream-text, but the biblical text was also regarded as belonging to the same category of texts. The similarities between midrash and oneirocriticism, i.e. the exegesis of Scripture and of dream-texts respectively, is to be attributed not only to the fact that midrash owes several of its hermeneutical rules to ancient oneirocritical methods, as shown by Lieberman, but also to the fact that the two text-types with which these interpretational practices were occupied belong to this particular textual category. I will conclude this article by elaborating somewhat on the analogies between Scripture and dream-text, and the interpretative practices of midrash and oneirocritics.

\section{Dream-text and Scripture}

The crucial question is in what way the Scripture and the dream-text, and the reading of these texts, might be considered analogous. How are the texts and the reading of them to be conceptualized in this analogy? Needless to say, the following short discussion will be replete with generalizations, and it will certainly not do justice either to the rich complexities and variety of opinion as regards rabbinic views of the Scripture, or to the rabbinic theories about the nature of dreams. I will nevertheless try to shed some light on the analogy between dream-text and Scripture by indicating some traits common to both types of text. ${ }^{29}$ These interrelated traits characterize the two types to some extent, and are distinctive of what makes them similar species of texts. Tentatively I will designate these particular textual traits as »transcendence», »semantic exuberance», and "ambiguity».

In rabbinic textual theory both of these text-types participate in an extra-rational epistemological sphere, and accordingly have the power to communicate to humans things that would otherwise not have been known by natural means. Hence they are conceived as more or less transcendent, and have the status of revelation or prophecy. But whereas Scripture unequivocally is considered to be of divine origin 
and might be characterized as the quintessence of prophecy, dreams are so only to some small degree. To be more precise: the dream is only »one-sixtieth part of prophecy» (bBer 57b). This calls for a few remarks on the rabbinic views on the nature of dreams, and I will outline the rabbinic conceptions that are pertinent to the subject at hand. ${ }^{30}$ The material that concerns dreams and their interpretation is distributed throughout the rabbinic corpus, and the discourse on the nature of dreams, as attested in this literature, is highly ambivalent and sceptical as to the prophetic status of dreams. The theories of dreams and the views on the interpreter's role are supposedly also, to some extent, subject to geographical differences (Palestinian rabbis/Babylonian rabbis) and changes during the course of time (tannaim/amoraim). ${ }^{31}$

$\mathrm{R}$. Jonathan, for example, is reported to have said that $" \mathrm{~A}$ man is shown in a dream only what is suggested by his own thoughts» (bBer 55b). Jonathan thereby displays a view that resembles Freud's notion about »day residues», i.e. dreams are the nocturnal processing of suppressed thoughts and events experienced during the day. ${ }^{32}$ Probably this particular statement does not rule out the possibility that some dreams are significant (Alexander 1995: 232f). But an even more sceptical stance towards dreams is evinced in a story in the Bavli. When rabbis Meir and Nathan, after they had tried to humiliate the nasi Simeon ben Gamaliel, were told in their dreams that they should go and pacify the nasi, Nathan heeded the advice, while Meir brushed it aside with the words, "Dreams are of no consequence» (bHor 13b; cf. also bGit 52a). This story illustrates the ambivalence that permeates the rabbinic discourse on the nature of dreams, as does the following passage from the Dreambook:

When Samuel had a bad dream, he used to say, And dreamers speak lies. ${ }^{33}$ When he had a good dream, he used to say, Do dreamers speak lies, seeing that it is written, I [God] speak with him in a dream ? $^{34}$

Rava pointed out a contradiction. It is written, And dreamers speak lies, and it is written, I speak with him in a dream.

There is no contradiction; in the one case it is through an angel, in the other through a demon. (bBer 55b)

Nevertheless, the opinion that dreams were prophetic, in some measure and under special circumstances, was probably the prevailing one during the Talmudic period, as might be inferred from 
several loci in the rabbinic literature. The dream was considered a species of prophecy, but a deficient or minor one - and as Hanina ben Isaac claimed, the dream was regarded as a kind of incomplete form of prophecy (GenR 17.5). In a parallel to this passage in the Genesis Rabba, the Talmud expresses the inferior prophetic status of the dream numerically: »A dream is one-sixtieth part of prophecy» (bBer $57 \mathrm{~b}$ ). The analogy between Scripture and dream-text is implied in the following statement of R. Yohanan: "If one rises early and a Scriptural verse comes to his mouth, this is a kind of minor prophecy» (bBer 55b). ${ }^{35}$ The visions one might have in the moment of waking up, when the mind is particularly susceptible to such experiences, are similar to a dream; hence they are a kind of minor prophecy, vbye vtucb. The opinion was, then, that a dream might contain both components that are "true», in the sense that they are likely to be fulfilled, and also wholly incidental features that have nothing to do with prophecy. In contradistinction to the midrashist's attitude towards Scripture, where every single dot or iota was considered charged with significance, the rabbis distinguished between irrelevant and meaningful elements in dreams. This stance seems to be reflected also when R. Yohanan says, in the name of Simeon ben Yohai, »that just as wheat cannot be without straw, so there cannot be a dream without some nonsense» (bBer 55a). This statement is immediately followed by a similar view, expressed by R. Berekhia: »While a part of a dream might be fulfilled, the whole of it is never fulfilled.»

What I hope is clear from this short summary is that there is a tendency in rabbinic dream theory to regard the dream-text as a bridge between man and something more transcendent, similar to the way Scripture is conceived. But humans, preferably of the rabbinic class, still have to participate in the creation of meaning in both text-types. In the cases of both midrash and oneirocritics, meaning is something that is produced through the reading of texts, as Faur has remarked in the context of midrash: »For the Hebrews meaning, signification, etc., are inseparable from text. Judaism does not recognize an a-textual problem: meaning is a function of text. The ultimate object of reading is not to discover the mind of the author, but to generate meaning. [...] Accordingly, meaning is not a given, it is not present; rather, it is the product of reading.» ${ }^{36}$ 
This productive reading of the dream-text and of the Scripture is conditioned by several common textual characteristics, apart from both texts being of transcendent origin. In rabbinic textual theory, Scripture is characterized by its semantic exuberance - i.e. there is in Scripture a superabundance of possible meanings coexisting in its textual strata, where they have always »already been deposited in a timeless substratum» (Scholem 1971: 289). This semantic fullness of Scripture is epitomized already in the first rabbinic document, the Mishna, when Ben Bag Bag states the dogma-like opinion that "everything» is contained in the Scripture: "Turn it and turn it again for everything is in it»vc vkufs vc lupvu vc lupv (Avot 5.22). This view is further elaborated in subsequent rabbinic literature, e.g. in the famous Talmudic passage which states that one biblical verse has the capacity to express several meanings at the same time, but that one and the same meaning never is deducible from several different verses (bSanh 34a). This semantic exuberance might be regarded as a consequence of the Scripture's strict semantic economy: words are never wasted in Scripture through repetition, and even if several verses appear to have the same meaning, according to the rabbinic reader there have to be semantic differences. And not only do two verses never say the same thing, but one and the same verse has the capacity to express several meanings at the same time, something that is further elaborated in the continuation of the above-mentioned Talmudic passage: »In R. Ishmael's school it was taught, And like a hammer that shatters rock, ${ }^{37}$ that is, just as the rock is split into many splinters, so also may one Biblical verse convey many teachings» (bSanh 34a).

This is one of the classic formulations of scriptural "polysemy» in the rabbinic corpus, and as such the notion of polysemy ensured that the semantic potential of the Scripture, its infinite abundance of meanings, was accessible to the rabbinic reader, whose task it was to »search out» all of these differing significances. Hence the hermeneutical possibilities were also endless, and the Scripture was regarded as forever fruitful. But whereas Scripture a priori was seen as endlessly meaningful, the importance of a dream was not as easily established, and the interpreter had to distinguish between meaningful, or prophetic, dreams and nonsense-dreams. And even in a dream regarded as meaningful, one had to make a distinction between significant 
components and nonsense or »superfluous material» ohkyc ohrcs (bBer 55a). Hence, only some dream-texts were considered important; but these on the other hand, as has been shown through the narrative examples above, seem to have been treated in a way similar to Scripture, as regards their semantic potential. They all testify to the ingenuity of the interpreter in producing multiple meanings from the same dreamtext. Both in midrash and in oneirocriticism the interpreters were de-contextualizing and atomizing their texts: the midrashist in what Kugel (1986: 94) called the »verse-centeredness» of midrashic reading; the dream-interpreter by treating the text as a kind of cipher, often using discrete words as hermeneutic keys. In both cases the interpreters also made full use of the ambiguities replete in both text-types. Pleonastic or redundant statements, contradictions, narrative gaps and irregularities in the textual surface, were jumped upon and used to their fullest potential. ${ }^{38}$

It may also be possible to discern in the dream-stories I have discussed an unconcerned attitude towards the problems of conflicting interpretations, equal to that shown in the realm of midrash according to Fisch: »The polysemic world of talmudic midrash appears to be utterly oblivious to the possibility that the type of multiple interpretation they practiced and encouraged could be considered problematic» (1997: 86). However, I strongly doubt that the rabbis were unaware of the hazards implied in the practice of multiple interpretations. On the contrary, I think that the phenomenon of dreaming itself, as well as the opportunity of human participation in the dream-text through interpretation, might have caused a great deal of anxiety. The rabbinic ambivalence regarding the nature of dreams, and also the ironic playfulness expressed in the dream-stories, testifies to this anxiety.

This ambivalence towards dreams and their interpretation, as well as the importance of these phenomena in rabbinic culture, was due to a twofold problem. On the one hand there was a theological problem arising from the notion of prophetic dreaming. The possibility that dreams might constitute a form of divination, hence a direct channel to the divine realm, was in conflict with the rabbinic »dogma» that prophecy had ceased at the time of Ezra. ${ }^{39}$ Revelation after Ezra was conceived as mediated through textual interpretation only, and thenceforth no one supposedly had any immediate contact with the 
divine any longer. But people's real experiences of divine intervention in dreams, and the comforting, ominous or other deep feelings associated with such nocturnal experiences, clashed with this conception and had to be coped with in some way. Moreover, the desire of ordinary people to understand their dreams equipped not only rabbis, but also non-rabbis, and sometimes even gentiles, with the possibility to exert influence on individuals or on the Jewish community through their interpretations. The ambivalence and differing opinions concerning dreams and their interpretation in the rabbinic literature testify to this dilemma. This, then, is the same kind of epistemological ambivalence that is connected with any notion of a sacred text of divine origin: »In the context of the paradoxes of monotheism in its correlation to human experience, the need to contain epistemological ambivalence may be a major reason for the central position of dreams. Along these lines, dreaming and dream interpretation may be understood as one of the expressive arenas in which a human and a superhuman perspective meet, communicate, and clash. Other such arenas are sacred texts and rituals» (Hasan-Rokem 1999: 223).

The status of Scripture is in some ways analogous to that of the dream, and consequently the discourse on scriptural revelation is also permeated by an epistemological ambivalence similar to that of the dream (Alvstad 2005). But while in the case of Scripture this ambivalence is given an ingenious solution through the rabbinic notions of an »Oral Torah», the problem offered by the notion of prophecy in dreams was not as easily dismissed. Whereas the Torah was not »in heaven» any longer, as it had been liberated from its divine origin and hence its author's authority by the rabbis, i.e. the community of its readers, ${ }^{40}$ the rabbis had not secured the control of divine words conveyed in dreams. Given this, it is obvious that dreams and their interpretation implied a double problem in rabbinic culture: a theological problem, since the idea of prophetic dreaming was at odds with the notion that prophecy had ceased; and a political one, since the control of the dream-text through its interpretation was not necessarily confined to rabbinic authority. Of this the rabbinic stories about dreams and their interpretation give ample illustrations. 


\section{Notes}

1. As Lieberman (1962: 75) writes: »We not only find the same methods employed in the onirocritica and in the Aggadah, but sometimes also come across the very same interpretation in both sources». Lieberman's seminal study of the relation between exegesis and dream interpretation is found in Hellenism in Jewish Palestine (1962: 68-82). Since the number of works treating the rabbinic view on dreams and dream interpretation in general is rather extensive, I will not try to make an exhaustive survey of this literature here. However, since two articles have been of particular significance to the subject matter at hand they deserve to be mentioned at the outset: one is Maren Niehoff's article "A Dream which is not Interpreted is like a Letter which is not Read» (1992), and the other piece of work I am indebted to is Philip Alexander's article »Bavli Berakhot 55a-57b: The Talmudic Dreambook in Context» (1995). Niehoff investigates the interconnection between scriptural exegesis and dream interpretation in early Palestinian Midrash, with particular focus on the genre of midrashic exegesis called petira. Alexander, on the other hand, discusses the section of the Babylonian Talmud called the Dreambook, which is the longest coherent text on dreams and their interpretation in the rabbinic corpus.

2. By »dream-text» I mean not the dream as experienced by the dreamer, but the dream as it is mediated after its completion. This mediation is usually made concrete through some kind of verbal representation, often in the form of a narrative told by the dreamer. The dream per se is never accessible once the dream experience is finished, not even to the dreamer, but it might still constitute the basis for its representation, i.e. for the dream-text.

3. In the following I will use existing translations, sometimes modified somewhat by me. The translations used are accounted for in the bibliography. Concerning the treatise on dreams in Bavli's tractate Berakhot 55a-57b, also known as »the Talmudic Dreambook», see especially Alexander (1995).

4. After the resolution of this story a discussion follows whether this dictum is Scriptural (as is suggested by the formula which introduces the dictum: »thus confirming that which is said»). This principle, however, is not found in the Bible. It is nevertheless provided with Scriptural support in the Talmud: »And as he interpreted for us, so it came to pass» (Gen. 41:13) Apart from in the narrative of the twenty-four dream interpreters rendered above (bBer 55b) this principle also occurs in the long story about the conflict between the dream-interpreter Bar Hedya and the rabbi Rava (bBer 56a). In this story the dictum is of central significance to the resolution of the story, and also has an important literary function as it marks the crisis of the whole story.

5. This also seems to be the import of a passage in the Palestinian Talmud, where R. Eliezer states that »a dream is fulfilled only in accord with its interpretation» (yMS 4:6). This passage is similar to the dictum in bBerakhot, but where the latter claims that dreams follow »the mouth», yMa'aser Sheni explicitly asserts that dreams follow their interpretation. The close affinity between these two statements, in the Babylonian Talmud and in the Palestinian Talmud respectively, is effectively underscored by the fact that they are given the same Scriptural support, Gen. 41. 13 (see note 4). This biblical verse is only cited once in each of the two Talmuds, and accordingly in connection with these two passages on dream interpretation. Other parallels to these statements, also supported by Gen. 41:13, are found elsewhere in the rabbinic corpus, for example in the two oldest exegetical midrashim, GenR 89:8 and LamR I.1.18; and also in two later midrashic compila- 
tions, Yalqut Shimoni and Sekhel Tov. (Cf. also with the statement ascribed to Bar Kappara in GenR 68:12 (»No dream is without its interpretation»), which however lacks the biblical proof-text imposed on the statements discussed above.)

6. If such an author of the dream should be imagined, and in the rabbinic literature it sometimes is, even if not in these two dicta, it could be identified with God if the dream is seen as prophetic, or with the dreamer and the dreamer's digestion, or experiences during the day, or other external factors. On the rabbinic views on the nature and prophetic status of dreams, see the discussion below.

7. This is apparent in many rabbinic stories, quite unambiguously, for instance, in the earlier mentioned story about the conflict between the dreaminterpreter Bar Hedya and rabbi Rava (bBer 56a). Below I will discuss several stories in which this theme is apparent.

8. The first time it appears in the Dreambook (bBer 55a) it is only enumerated as one of half a dozen various sayings about dreams attributed to R. Hisda.

9. After this statement follow the nine scriptural verses which ought to be recited if one wants to procure a positive outcome of the dream.

10. Here I follow closely Alexander's (1995: 235f) interpretation of this Talmudic passage. But this is a somewhat simplifying interpretation, since it does not take into account different versions and editorial emendations manifest in parallel readings of this difficult passage. The three persons mentioned in the text are, for example, probably not to be identified with a minor bet din, as Alexander proposes. In a manuscript version they are described as three persons "who love him [the dreamer]», a qualification that the printed edition lacks. The formula should accordingly be recited in front of three persons sympathetic to the dreamer. Of greater significance to the import of this passage is, however, the fact that one reading entirely lacks the anonymous editorial use of Hisda's dictum as a means to oppose Yohanan's initial statement. It is therefore questionable if this editorial insertion is an integral part of the text. This is not the place, however, to delve into the editorial and textual intricacies of this problematic passage; see instead Stemberger (1976: 27); Kalmin (1994: 71f); Afik (1990: 27, n.3). There are, nevertheless, other examples of how good interpretations put on bad dreams in fact turn these dreams into portents of personal success for the dreamer, e.g. the story in yMS 4: 6 in which it is reported that one of R. Akiva's students is given three pieces of bad news in a dream, and that Akiva by putting favourable interpretations on these news transformed them into good omens. (A parallel version of this story appears in LamR I:1:16, but here the dreamer is said to be a disciple of R. Yohanan.)

11. Apart from the fact that a favourable interpretation put on a disturbing dream in itself has the power to cancel the potentially dangerous effects of the dream (see note 10), there are also several instances in the Dreambook, and elsewhere in the rabbinic literature, where the reading of biblical verses is supposed to neutralize bad dreams and procure a good outcome of them. Other methods to counter bad dreams mentioned by the rabbis, besides the method of hatavat halom or "turning of the dream», are the ta'anit halom or »dream-fast» (bShab 11a, bTa $12 \mathrm{~b}$ ), and the »dream-prayer» (bBer 55b). Concerning rabbinic methods to secure good dreams, see e.g. Trachtenberg (2004: 244-248); Kalmin 1994: 70-77; Ensiqlopedia Talmudit (1957, "Hatavat halom», vol. VIII, cols. 753-758).

12. Niehoff (1992: 58, n. 2) points out that the letter as a means for divine prophecy is used already in the Bible (2 Chron. 21:12-21). (That divine messages were conveyed in the form of letters is not unheard of in the Near Eastern context; cf. Foster (1995: 214) who exemplifies this with two letters from the gods Ishtar and Shamash to Zimri-Lim, king of the Syrian city of Mari in the 19th century B.C.E.) 
But as I read this Talmudic passage the rabbis rather undermine or play with this notion of prophecy mediated through a letter, when they change the direction of communication, and instead of depicting a divine message communicated to man through a letter they bring forward the (possibly prophetic) message as something constructed by those who have the power to interpret the dream-text. But my interpretation is, in this case, equivocal, since the rabbis in the discussion above finally plead for God's help in turning this dream into something good.

13. Freud's thesis is that free association is one of the basic method of interpreting dreams. This method is dependent on the dreamer's free associations, and not on any preconceived system of symbols.

14. That the rabbis' conception of the dream-text is similar to reader-response critics' attitude towards the "normal» text has been touched briefly upon by Niehoff (1992: 59, n. 9; see also p. 65).

15. »Reader-response criticism» (or »reception aesthetics») designates a reader-oriented approach to fictional texts (and sometimes also to non-fictional texts), which claims that texts ultimately acquire their meaning with the assistance of the reader's participation. This participation, they argue, is wholly in accord with the text's nature, since one of the characteristics of a text is its indeterminacy. During the act of reading these textual gaps and indeterminacies perform the function of stimuli for the readers, and incite them to generate meaning in interaction with the text's latent semantic potential. Hence a literary text (like many other texts as well) does not just mean something, it does not have a fixed and static meaning inherently residing in it; instead it functions as a blueprint or a guide to the readers, with the assistance of which the readers themselves create meaningful content. See e.g. Iser (1980, especially pp. 107-134, 163-179); Fish (1980).

16. Gen. 41:13. See notes 4 and 5.

17. This story in Lamentations Rabba might be read as a narrative commentary on the aforementioned scriptural passage in Gen. 41:13 (see notes 4 and 5). Other renderings of this story are found in Bereshit Rabba (GenR 89:8) and in Talmud Yerushalmi (yMS 4:6). (Cf. also the remarkable modern parallel to this story that Hasan-Rokem relates (1999: 23of, n. 10).) The saying about wine, here ascribed to R. Yohanan, has a parallel in bBer 57a, where it is written that a tanna in the presence of R. Yohanan recited a teaching about the significance of wine in dreams, a teaching that R. Yohanan subsequently emends. R. Abbahu's saying is reiterated in GenR 68:12, and also has a parallel in bSan $30 a$.

18. I will not make any thorough analysis of this long story here. It has been discussed by e.g. Kalmin (1994: 67-69), and Alexander (1995: 235, 246f).

19. Deut. 28.31; the verse continues: "... but you shall not eat of it.»

20. Deut. 28.41; the verse continues: »...for they shall go into captivity.»

21. Pace Stern (1996: 100)

22. Concerning R. Ishmael b. Yose as dream-interpreter, see for example the series of stories about him in yMS 4:6 and in bBer 56b; see also Zeitlin (1970: 16f). $\mathrm{He}$ is, however, not to be confused with his earlier tannaitic namesake, R. Ishmael ben Elisha, to whom are ascribed the thirteen middot, or hermeneutical rules, for Bible interpretation. R. Ishmael ben Elisha is, nevertheless, also mentioned in the Talmudic Dreambook (bBer 57b), and in this context he appears as an ominous dream-symbol: the person who sees R. Ishmael in a dream might expect some kind of punishment. (R. Ishmael is supposed to have suffered martyrdom under the Romans and this might be the reason for his significance as dream-symbol.)

23. The story has a parallel in LamR I.1.15.

24. Concerning this subject in the context of scriptural interpretation and 
the development of halakhah, see e.g. Berger (1998: 83-96).

25 Variations of this motif are found in e.g. the long story of the Samaritan who sold interpretations of dreams to unsuspecting dreamers, but was exposed by R. Ishmael b. Yose (LamR I.1.14; cf. also yMS 4:6), and, most unequivocally, in the Bar Hedya story (bBer $56 a-56 b$ ). The motif of bringing shame on a rabbi, primarily in the Bavli, has been investigated by e.g. Rubenstein (1999; 2003, especially pp. 67-79).

26. The dream-narratives in the Palestinian Talmud and those in the midrashim of Palestinian origin tend, for instance, to polemize against the Samaritans. This theme is absent in the Babylonian Talmud.

27. This conclusion might of course be contested, not least because of the multifarious nature of the material on dreams in the rabbinic corpus. Nevertheless, I find this to be the predominant view on the interpretation of dreams, which permeates both the Bavli's Dreambook (bBer 55a-57b) and the Palestinian equivalents to this Dreambook in the Yerushalmi's tractate Ma'aser Sheni 4:6, and in Midrash Lamentations Rabba I.1.14-18. In the Dreambook it is particularly the central story of Bar Hedya that persuasively guides the reader of the Dreambook to the conclusion that the interpreters were credited with an almost unrestricted authority in the business of dream interpretation, and that the dream-text (similar to the biblical text) was conceived as inherently polysemic. These themes I consider to be the main thrusts also in the Yerushalmi, as attested in Ma'aser Sheni 4:6, and in the Lamentations Rabba, even if »authentic» dream-interpreters unequivocally are depicted as persons belonging to the rabbinic class in these works.

28. E.g. Cicero in De Divinatione 2. 70. About this passage in Cicero, see Oppenheim (1956: 210); Lieberman (1962: 77); Alexander (1995: 236).

29. For further discussions on the analogy between dream-texts and biblical texts, see also Lieberman (1962); Alexander (1995); Niehoff (1992).

30. For a general treatment on the subject of rabbinic dream-theory, see Afik (1990) and Stemberger (1976); for a systematic commentary on the material on dreams in the Talmud, Kristianpoller (1923) is the most complete work; a historical study is given in Zeitlin (1970); and in the context of superstition and folk religion, see Trachtenberg (2004); concerning the Talmudic Dreambook's agenda, see Alexander (1995); see also »Dreams: In the Talmud» in Encyclopaedia Judaica (vol. VI, cols. 209-210); and »Divrei halomot.» (vol. VII, cols. 84-91) in Ensiqlopedia Talmudit.

31. For a discussion of this subject, see Kalmin (1994: 61-80).

32. A similar view seems to be ascribed also to R. Yose, cf. yMS 4:6.

33. Zech. 10.2.

34. Num. 12.6.

35. Cf. also the parallel in bBer $57 \mathrm{~b}$.

36. Faur (1986: xxxvii). The question whether this is something uniquely distinctive for the »Hebrews» or »Judaism» will not be discussed here. Faur (1986: 122f) too has commented on the close connections between the interpretational practices of midrash and oneirocritics.

37. Jer. 23:29.

38. For the interpreter's use of textual characteristics like these, see e.g. Stern (1994:74-82); Kugel (1986: 92-99).

39. Regarding the end of prophecy, cf. e.g. Urbach (1945).

40. As is illustrated in e.g. bBM 59a-b. The discussions of this important Talmudic passage are numerous, see e.g. Boyarin (1990); Fisch (1997). 


\section{Literature}

\section{Primary Sources}

Bereshit Rabba, Jerusalem, reprint of Vilna edition, Vilna, 1878; Theodor-Albeck edition, Berlin, 1903, 1912, 1929.

Eikha Rabba, Jerusalem, reprint of Vilna edition, 1878; Buber edition, Vilna, 1899.

Midrash Sekhel Tov, Buber edition, 1900/1901. Reprint Tel Aviv, n.d.

Mishna, Albeck, Shisha Sidre Mishnah, 6 vols., Jerusalem, 1952-58.

Talmud Bavli, Steinsaltz edition, Jerusalem, 1967; Romm edition, Vilna, 1880-86.

Talmud Yerushalmi, Venice, 1523.

Yalqut Shimoni, Jerusalem, 1960, reprint of Warsaw, 1878.

\section{Translations}

Hebrew-English Edition of the Babylonian Talmud. Tractates: „Berakhoth», in vol. 1, translated by M. Simon, 1990; "Sanhedrin, in vol. 19, translated by J. Shachter \& H. Freedman, 1987. The Soncino Press, London.

JPS Hebrew-English Tanakh. The Traditional Hebrew Text and the New JPS Translation. 2nd Edition. Jewish Publication Society, Philadelphia. 1999 [First ed. 1985].

Midrash Rabbah. Genesis. Volume 2. Translated by H. Freedman. The Soncino Press, London \& New York. 1983.

Midrash Rabbah. Lamentations. Translated by A. Cohen. The Soncino Press, London \& New York. 1983.

The Mishnah. Translated by H. Danby. Oxford University Press, Oxford. 1992 [First ed. 1933].

The Talmud of the Land of Israel. A Preliminary Translation and Explanation. Volume 8. Maaser Sheni. Translated by R. Brooks. The University of Chicago Press, Chicago \& London. 1993.

\section{Secondary Literature}

Afik, Yitshak. 1990. Tefisat ha-halom etsel Hazal. (Ph.D. thesis, Bar-Ilan University.)

Alexander, Philip S. 1995. »Bavli Berakhot 55a-57b: The Talmudic Dreambook in Context.» Journal of Jewish Studies, Vol. 46, Nos. 1-2, pp. 230-248.

Alvstad, Erik. 2005. "Dispyter i Himlens namn. Den heliga textens ambiguitet och rabbinsk tolkning.» In: Litteraturen og det Hellige (Ed. by Davidsen, Ole \& Klint, Stefan \& Nielsen, Kirsten) Aarhus University Press. Aarhus. [Forthcoming]

Berger, Michael S. 1998. Rabbinic Authority. Oxford University Press, Oxford \& New York.

Boyarin, Daniel. 1990. Intertextuality and the Reading of Midrash, Indiana University Press, Bloomington \& Indianapolis.

Faur, José. 1986. Golden Doves with Silver Dots. Semiotics and Textuality in Rabbinic Tradition. Indiana University Press, Bloomington.

Fisch, Menachem. 1997. Rational Rabbis. Science and Talmudic Culture. Indiana University Press, Bloomington \& Indianapolis.

Fish, Stanley. 1980. Is There a Text in This Class? The Authority of Interpretive Communities. Harvard University Press, Cambridge \& London.

Foster, Benjamin R. 1995. From Distant Days. Myths, Tales, and Poetry of Ancient Mesopotamia. CDL Press, Bethesda, Maryland.

Hasan-Rokem, Galit. 1999. "Communication with the Dead in Jewish Dream Culture.» In: Dream Cultures. Explorations in the Comparative History of Dreaming. (Ed. by Shulman, David \& Stroumsa, Guy G.) Pp. 213-232. Oxford University Press, Oxford \& New York. 
Holland, Norman. 1993. »Foreword: The Literarity of Dreams, the Dreaminess of Literature.» In: The Dream and the Text. Essays on Literature and Language. (Ed. by Rupprecht, Carol Schreier) Pp. ix-xxii. State University of New York Press (SUNY Series in dream studies), Albany.

Iser, Wolfgang. 1980 (1978). The Act of Reading. A Theory of Aesthetic Response. John Hopkins University Press, Baltimore \& London.

Kalmin, Richard. 1994. Sages, Stories, Authors, and Editors in Rabbinic Babylonia. Scholars Press, Atlanta, Georgia.

Kristianpoller, Alexander. 1923. Traum und Traumdeutung im Talmud. Monumenta Talmudica, Bd. 4, T. 2, H. 1. Benjamin Harz Verlag, Vienna and Berlin. (Reprint: Wissenschaftliche Buchgesellschaft, Darmstadt. 1972.)

Kugel, James L. 1986. "Two Introductions to Midrash.» In: Midrash and Literature. (Ed. by Hartman, Geoffrey H. \& Budick, Sanford) Pp. 77-103. Yale University Press, New Haven \& London.

Lieberman, Saul. 1962 [revised ed. of 1950]. Hellenism in Jewish Palestine. Studies in the Literary Transmission Beliefs and Manners of Palestine in the I Century B.C.E. - IV Century C.E. (Series: Texts and Studies of The Jewish Theological Seminary of America, Vol. XVIII). The Stroock Publications Fund, New York.

Niehoff, Maren. 1992. »A Dream which is not Interpreted is like a Letter which is not Read.» Journal of Jewish Studies, Vol. 43, No. 1, pp. 58-84.

Oppenheim, Leo A. 1956. »The Interpretation of Dreams in the Ancient Near East.» Transactions of the American Philosophical Society, New Series, Volume 46, part 3, pp. 184-255.

Rubenstein, Jeffrey L. 1999. Talmudic Stories. Narrative Art, Composition, and Culture. The John Hopkins University Press, Baltimore \& London.

Rubenstein, Jeffrey L. 2003. The Culture of the Babylonian Talmud. The John Hopkins University Press, Baltimore \& London.

Scholem, Gershom. 1971. »Revelation and Tradition as Religious Categories in Judaism». In: The Messianic Idea in Judaism and Other Essays on Jewish Spirituality. Pp. 282-303. Schocken Books, New York.

Stemberger, Brigitte. 1976. "Der Traum in der rabbinischen Litteratur.» Kairos, N.F. 18 , pp. $1-42$.

Stern, David. 1994 [1991]. Parables in Midrash. Narrative and Exegesis in Rabbinic Literature. Harvard University Press, Cambridge \& London.

Stern, David. 1996. Midrash and Theory. Ancient Jewish Exegesis and Contemporary Literary Studies. Northwestern University Press, Evanston.

Trachtenberg, Joshua. 2004 [1939]. Jewish Magic and Superstition. A Study in Folk Religion. University of Pennsylvania Press, Philadelphia.

Urbach, Ephraim A. 1945. »Matai paseqa ha-nevua?» Tarbiz, Vol. 17, No. 1, pp. 1-11.

Walde, Christine. 1999. „Dream Interpretation in a Prosperous Age? Artemidorus, the Greek Interpreter of Dreams.» In: Dream Cultures. Explorations in the Comparative History of Dreaming. (Ed. by Shulman, David \& Stroumsa, Guy G.) Pp. 121-142. Oxford University Press, Oxford \& New York.

Zeitlin, Solomon. 1970. »Dreams and Their Interpretation from the Biblical Period to the Tannaitic Time: An Historical Study.» Jewish Quarterly Review, Vol. 66, pp. 1-18.

Encyclopaedias

Encyclopaedia Judaica. »Dreams: In the Talmud» (vol. VI, cols. 209-210, A. Arzi), Jerusalem. 1971.

Ensiqlopedia Talmudit. »Divrei halomot» (vol. VII, cols. 84-91, 1956); »Hatavat halom» (vol. VIII, cols. 753-758, 1957). 